\title{
Ghrelin suppresses noradrenaline release in the brown adipose tissue of rats
}

\author{
Asuka Mano-Otagiri, Hisayuki Ohata, Azusa Iwasaki-Sekino, Takahiro Nemoto \\ and Tamotsu Shibasaki
}

Department of Physiology, Nippon Medical School, 1-1-5 Sendagi, Bunkyo-ku, Tokyo 113-8602, Japan

(Correspondence should be addressed to A Mano-Otagiri; Email: asuka@nms.ac.jp)

\begin{abstract}
To clarify the role of ghrelin in the regulatory mechanism of energy metabolism, we analyzed the effects of centrally and peripherally administered ghrelin on noradrenaline release in the brown adipose tissue (BAT) of rats using a microdialysis system. I.c.v. administration of ghrelin at a dose of $500 \mathrm{pmol}$ suppressed noradrenaline release in BAT, and microinjection of ghrelin $(50 \mathrm{pmol})$ into the paraventricular nucleus (PVN) or arcuate nucleus (ARC) of the hypothalamus also suppressed noradrenaline release in BAT. In addition, i.v. administered ghrelin $(30 \mathrm{nmol})$ suppressed noradrenaline release in BAT, and this suppression was blocked by a
\end{abstract}

vagotomy. Neither i.c.v. nor i.v. administration of des-acyl ghrelin, which does not bind to GH secretagogue receptor type 1a (GHS-R1a), affected noradrenaline release in BAT. These results indicate that ghrelin increases energy storage by suppressing the activity of the sympathetic nerve innervating BAT. It seems that the PVN and ARC, which express GHS$\mathrm{R} 1 \mathrm{a}$, are the sites of action of ghrelin in the brain and that the action of peripheral ghrelin on the sympathetic nerve activity innervating BAT is mediated by the vagal nerve, which also expresses GHS-R1a.

Journal of Endocrinology (2009) 201, 341-349

\section{Introduction}

Ghrelin was isolated from the rat stomach extracts (Kojima et al. 1999) as an endogenous ligand for GH secretagogue receptor (GHS-R; Howard et al. 1996, Smith et al. 1997). Alternative mRNA processing of the rat GHS-R gene transcript generates two products, GHS-R1a and GHS-R1b (McKee et al. 1997). The former isoform functions by binding ghrelin/GHS while the latter is non-functional (Howard et al. 1996). Ghrelin/GHS stimulates not only GH secretion but also food intake through GHS-R1a when administered centrally or peripherally (Okada et al. 1996, Nakazato et al. 2001, Date et al. 2002, Tamura et al. 2002). Ghrelin increases Fos expression in the ventromedial nucleus, dorsomedial nucleus, suprachiasmatic nucleus, arcuate nucleus (ARC), and paraventricular nucleus (PVN) of the hypothalamus when administered i.c.v. or peripherally, and GHS-R1a is expressed in these nuclei (Lawrence et al. 2002, Rüter et al. 2003, Kobelt et al. 2005, Mano-Otagiri et al. 2006, Zigman et al. 2006). The GHS-R1a expressed in GHRH neurons is mainly involved in ghrelin/GHS-induced GH secretion (Tannenbaum et al. 2003). We have shown that GHS-R1a expressed in GHRH neurons upregulates GHRH gene expression (Mano-Otagiri et al. 2006). Ghrelin administered i.c.v. or peripherally also increases the respiratory quotient $(R Q)$, indicating its inhibitory action on fat expenditure (Tschöp et al. 2000). Furthermore, the microinjection of ghrelin into the PVN or ARC increases food intake and RQ (Currie et al. 2005). Therefore, the central effect of ghrelin on energy homeostasis may be mediated through the activation of GHS-R1a in the PVN and ARC.

Brown adipocytes are important in the regulation of energy metabolism by increasing energy expenditure through thermogenesis (Lowell \& Spiegelman 2000), and the activity of brown adipocytes is stimulated by the sympathetic nerves (Lowell \& Spiegelman 2000). I.c.v. administration of ghrelin suppresses the electrophysiological activity of the sympathetic nerves innervating brown adipose tissue (BAT) in rats anaesthetized with urethane and chloralose (Yasuda et al. 2003). These findings suggest that ghrelin induces a positive energy balance not only by increasing food intake but also by decreasing energy expenditure.

We developed a microdialysis system in which the release of noradrenaline, an important stimulator of brown adipocytes, is monitored in BAT in freely moving rats. In the present study, we used this system to test the effect of i.c.v. administration of ghrelin or microinjection of ghrelin into the PVN or ARC on noradrenaline release in BAT. Our goal was to determine if i.c.v. administration of ghrelin inhibits noradrenaline release in BAT and if those hypothalamic nuclei are involved in the inhibitory action of ghrelin on the sympathetic nerves innervating BAT. Furthermore, the effect 
of i.v. administration of ghrelin on noradrenaline release in BAT was analyzed; the effect was further examined in bilateral vagotomized rats to clarify the pathway of peripheral ghrelin signals to BAT, since GHS-R1a is expressed in vagal nodose ganglion (Sakata et al. 2003, Burdyga et al. 2006).

\section{Materials and Methods}

\section{Animals}

Male Sprague-Dawley rats (SLC, Shizuoka, Japan), 7-8 weeks old, were used in this study. Rats were housed individually in each cage $(20 \times 25 \times 18 \mathrm{~cm})$ and maintained at $24^{\circ} \mathrm{C}$ on a $12 \mathrm{~h}$ light: $12 \mathrm{~h}$ darkness (light on at $0800 \mathrm{~h}$, off at $2000 \mathrm{~h}$ ). They were allowed access to laboratory chow and distilled water ad libitum. All experimental procedures were conducted in accordance with the guidelines for the use and care of laboratory animals from the ethics committee of Nippon Medical School.

\section{Surgical procedure}

To administer samples i.c.v., a polyethylene cannula was implanted into the right lateral ventricle and fixed to the skull with three screws and acrylic dental cement under sodium pentobarbital anesthesia (50 mg/ $\mathrm{kg}$ of body weight, i.p.), as previously described, 5 days before the experiment (Mano-Otagiri et al. 2006).

For microinjection of samples into the PVN or ARC, a 24-gauge stainless guide cannula was implanted and fixed to the skull with three screws and acrylic dental cement. Stereotaxic coordinates, as determined from the atlas of Paxinos \& Watson (1996) were just above the PVN (rostral, $-1.8 \mathrm{~mm}$; lateral, $0.3 \mathrm{~mm}$; and ventral, $-6.2 \mathrm{~mm}$, relative to the bregma and the brain surface) or ARC (rostral, $-3.8 \mathrm{~mm}$; lateral, $0.3 \mathrm{~mm}$; and ventral, $-8 \cdot 1$ ) under sodium pentobarbital anesthesia $(50 \mathrm{mg} / \mathrm{kg}$ of body weight, i.p). A dummy cannula was inserted into the entire length of each guide cannula in order to prevent obstruction. After surgery, all rats were individually housed and allowed to recover for at least 6 days.

For i.v. injection of sample, an i.v. catheter was inserted into the right external jugular vein of rats under sodium pentobarbital anesthesia $(50 \mathrm{mg} / \mathrm{kg}$ of body weight, i.p.; Thrivikraman et al. 2002) 4 days before the experiments.

To examine the effect of a vagotomy, a truncal vagotomy (or a sham operation as a control) was performed 7 days before the i.v. catheter insertion. After a midline incision of the abdominal wall, the lower part of the esophagus was exposed and the anterior and posterior branches of the vagal nerve were incised under anesthesia with sodium pentobarbital $(50 \mathrm{mg} / \mathrm{kg}$ of body weight, i.p.), as previously described (Smith et al. 1981). During the sham operations, the vagal trunks were similarly exposed without any cutting of the vagal nerve.

\section{Microdialysis of noradrenaline in BAT}

On the day of the experiment, the skin in the interscapular area was shaved and cleaned with $70 \%$ ethanol, and a small incision was made along the midline, exposing a depot of white fat and the underlying interscapular brown fat. A microdialysis probe (OP-100-05; Eicom Corp., Kyoto, Japan) with a 5-mm dialyzable membrane was inserted into either lobe of the brown fat lobes under light anesthesia with ether (Gabaldón et al. 2003). The end of the probe was exteriorized through the midscapular skin incision, and the skin incision was then sutured close. After the rat had recovered from anesthesia, the probe was connected with tubing for microdialysis, and microdialysis was performed under free-moving conditions without chow and water between 1100 and $1800 \mathrm{~h}$. The probe was continuously perfused with Ringer's solution (147 mM NaCl, $4 \mathrm{mM} \mathrm{KCl}$, and $2 \cdot 3 \mathrm{mM} \mathrm{CaCl}_{2}, \mathrm{pH} 7 \cdot 0$ ) at a flow rate of $2 \mu \mathrm{l} / \mathrm{min}$, and the dialysate was collected every $20 \mathrm{~min}$. Noradrenaline concentrations in dialysates $(40 \mu \mathrm{l} / 20 \mathrm{~min})$ were determined by a combination of HPLC and electrochemical detection by an Eicompak CA-5ODS column $(2 \cdot 1 \mathrm{~mm}$ i.d. $\times 150 \mathrm{~mm}$; Eicom) and a WE-3G graphite electrode (Eicom) set at $+450 \mathrm{mV}$ against an $\mathrm{Ag} / \mathrm{AgCl}$ reference electrode. The electrode's current sensitivity was $0.1 \mathrm{nA}$. The minimum detection limit of noradrenaline in the system was $0 \cdot 1 \mathrm{pg}$. The mobile phase in the HPLC column was $0.1 \mathrm{M}$ sodium phosphate buffer $(\mathrm{pH} \quad 6.0$ ) containing $1.85 \mathrm{mM}$ sodium octanesulfonic acid, $0.17 \mathrm{mM}$ EDTA, and 5.0\% (v/v) methanol. After a $3 \mathrm{~h}$ stabilization period, the baseline noradrenaline levels were defined as the average release in three consecutive fractions immediately preceding the injection and were considered as $100 \%$. Rats then received an injection of rat ghrelin (Peptide Institute, Inc., Osaka, Japan).

Ghrelin at a dose of 50 or 500 pmol dissolved in $2 \mu \mathrm{l}$ of saline (or $2 \mu \mathrm{l}$ of saline as a control) was administered i.c.v. through the guide cannula. Ghrelin at a dose of $50 \mathrm{pmol}$ dissolved in $0.5 \mu \mathrm{l}$ of saline (or $0.5 \mu \mathrm{l}$ of saline as a control) was microinjected into the PVN or ARC. Ghrelin at doses of 6 or $30 \mathrm{nmol}$ dissolved in $0.5 \mathrm{ml}$ saline (or $0.5 \mathrm{ml}$ saline as a control) was i.v. administered. Each administered dose of ghrelin was determined by its stimulatory effect on food intake as determined in previous reports, $10 \mathrm{pmol}$ to $1 \mathrm{nmol}$ for i.c.v. administration, 15-60 pmol for microinjection into the brain, and 1.5-10 nmol for i.v. administration (Nakazato et al. 2001, Date et al. 2002, Currie et al. 2005). We also administered rat des-acyl ghrelin (Peptide Institute, Inc.), which does not bind to GHS-R1a, at a dose of 500 pmol for i.c.v. experiment or $30 \mathrm{nmol}$ for i.v. experiment to certify that the action of ghrelin is mediated by GHS-R1a.

\section{Histology}

To verify the placement of the cannula, rats were deeply anesthetized with sodium pentobarbital at the end of the experiment, and dye $(0.5 \mu \mathrm{l}$ Brilliant Blue 6B; Tokyo Kasei, 
Tokyo, Japan) was then injected into the microinjection cannula. The brain was fixed with $10 \%$ formaldehyde via intracardiac infusion. Coronal sections were then made, and the injection site was localized according to the atlas (Paxinos \& Watson 1996). The images were captured with an image analysis system (microscope; $\mathrm{B} \times 50$, objective lens; $4 \times$, OLYMPUS, Tokyo, Japan, camera; Power HAD, SONY, Tokyo, Japan, detector; MCID Elite Version 6.0, Amersham Biosciences).

\section{Northern blotting analysis of uncoupling protein $1 \mathrm{mRNA}$ in $B A T$}

To examine the effect of ghrelin on uncoupling protein (Ucp) 1 mRNA expression in BAT, rats were killed by decapitation 3 or 6 h after i.c.v. or i.v. administration of sample and BAT was removed and stored at $-80{ }^{\circ} \mathrm{C}$.

Total RNA was extracted from rat tissues using the AGPC method. Ucp1 cDNA was amplified from BAT RNA using 5'-CCGGATCCAGGCTTCCAGTACTATTAG-3' (sense) and 5'-CCGAATTCGCCACCCGTCATCAAGCCA-3' (antisense) primers, which range from 310 to 547 (NCBI: BC088156). The amplified cDNA was subcloned into pGEM $3 Z$ vector (Promega). Plasmid vector was digested by EcoRI and BamHI, and the $233 \mathrm{bp}$ Ucp1 cDNA fragment was labeled using a digoxigenin (DIG) DNA labeling and detection kit (Roche Diagnostics $\mathrm{GmbH}$ ). Twenty micrograms of total RNA was separated with $0 \cdot 8 \%$ agarose gel and transferred to a positively charged nylon membrane (Roche). The membranes were fixed by u.v. cross linking and pre-hybridized in high SDS-buffered solution (7\% SDS, $50 \%$ formamide, $5 \times \mathrm{SSC}, 50 \mathrm{mM}$ sodium phosphate, $\mathrm{pH} 7 \cdot 0,0 \cdot 1 \% \mathrm{~N}$-lauroylsarcosine, and $50 \mu \mathrm{g} / \mathrm{ml}$ yeast tRNA) at $55^{\circ} \mathrm{C}$ for $2 \mathrm{~h}$. DIG-labeled DNA probe was added and hybridized at $55^{\circ} \mathrm{C}$ for $48-72 \mathrm{~h}$. The membranes were then washed and primed with anti-DIG antibody conjugated with alkaline phosphatase. The signals were detected on Fuji Las 1000 (Fuji film, Tokyo, Japan) using CDP star detection reagent (Amersham Biosciences). Quantification of the bands was performed using an NIH image (developed by Dr Wayne Rasband; available via http://rsb.info.nih.gov), and the intensity of the bands was corrected using the density of the $18 \mathrm{~S}$ rRNA bands. The Ucp1 mRNA level was expressed as a percentage of the control group (rats receiving saline).

\section{RT-PCR}

The tissue samples of hypothalamus, pituitary, epididymal WAT and BAT were obtained from five rats after decapitation and they were then stored at $-80{ }^{\circ} \mathrm{C}$. Total RNA was extracted from rat tissues using AGPC method. To avoid false positive results caused by DNA contamination, a DNase treatment for $60 \mathrm{~min}$ at $37^{\circ} \mathrm{C}$ using RNase-free DNase (Takara, Shiga, Japan) was done. First strand cDNA was synthesized using $1 \mu \mathrm{g}$ of denatured total RNA under conditions of $42^{\circ} \mathrm{C}$ for $30 \mathrm{~min}, 99^{\circ} \mathrm{C}$ for $5 \mathrm{~min}$, and $5{ }^{\circ} \mathrm{C}$ for 5 min using a RT-PCR kit (Takara). PCR was carried out under conditions of denaturation at $94{ }^{\circ} \mathrm{C}$ for $10 \mathrm{~s}$, annealing at $55^{\circ} \mathrm{C}$ for $5 \mathrm{~s}$, and extension at $72{ }^{\circ} \mathrm{C}$ for $30 \mathrm{~s}$ for 45 cycles, using specific primers for rat GHS-R 1 a (sense: $5^{\prime}$-ccagaaccacaagcagacagtga- $3^{\prime}$; and antisense: $5^{\prime}$-gatggcagcgctgaggtagaa- $3^{\prime}$ ), rat GHRH $\left(5^{\prime}\right.$-actctgggtgttctttgtgc- $3^{\prime}$; and antisense: $5^{\prime}$-atcttt gttcctggttcctc- $3^{\prime}$ ), rat $\mathrm{GH}$ (sense: $5^{\prime}$-ggatccatggctgcagactctcagactcc $-3^{\prime}$; and antisense: $5^{\prime}$-ctcgagctagaaagcacagctgctttccg- $3^{\prime}$ ), rat Ucp1 (sense: $5^{\prime}$-ccggatccaggcttccagtactattag- $3^{\prime}$; and antisense: $5^{\prime}$-ccgaattcgccacccgtcatcaagcca- $3^{\prime}$ ), rat leptin (sense: $5^{\prime}$-acggaggaaaatgtgctggag- $3^{\prime}$; and antisense: $5^{\prime}$-ggtgacaatggtcttgatgaggg- $3^{\prime}$ ), and rat GAPDH (sense: $5^{\prime}$-ggcacagtcaaggctgagaatg- $3^{\prime}$; and antisense: $5^{\prime}$-atggtggtgaagacgccagta- $3^{\prime}$ ). After amplification, the PCR products were subjected to $2 \cdot 2 \%$ agarose gel electrophoresis, stained with $0.5 \mathrm{mg} / \mu \mathrm{l}$ ethidium bromide, and were then visualized under u.v. illumination.

\section{Data analysis}

All results are expressed as mean \pm s.E.M. The data were subjected to two- or three-way repeated-measures ANOVA with ghrelin injection, surgical operation, and time as factors. The data of basal noradrenaline release in sham-operated rats and vagotomized rats and Ucp1 expression in BAT were subjected to one-way ANOVA. Subsequently, Fisher's PLSD test for multiple comparisons was used. $P$ values $<0 \cdot 05$ were considered statistically significant.

\section{Results}

Typical histological sections indicating the location of the probes inserted into the PVN or ARC are shown in Fig. 1. Only data obtained from rats in which the tip of the injection needle was inserted into the PVN or ARC were used for the statistical analysis. The data from rats in which the tip of the injection needle was not inserted into the PVN or ARC were shown as misplacement controls in Fig. 2A.

\section{Inhibitory effect of i.c.v. ghrelin on noradrenaline release in BAT}

The effect of i.c.v. administration of ghrelin at a dose of 50 or 500 pmol on noradrenaline release in BAT is shown in Fig. 3A. There was a significant interaction between ghrelin injection and time $\left(F_{16,72}=3 \cdot 14 ; P<0 \cdot 005\right)$. Further analysis revealed that i.c.v. administration of ghrelin at a dose of $500 \mathrm{pmol}$ but not $50 \mathrm{pmol}$ significantly suppressed noradrenaline release in BAT dialysates $0-20$ and 20-40 min after injection $(P<0 \cdot 05)$. The effect of i.c.v. administration of des-acyl ghrelin at a dose of $500 \mathrm{pmol}$ on noradrenaline release in BAT is shown in Fig. 3B. Des-acyl ghrelin did not affect noradrenaline release in BAT. 

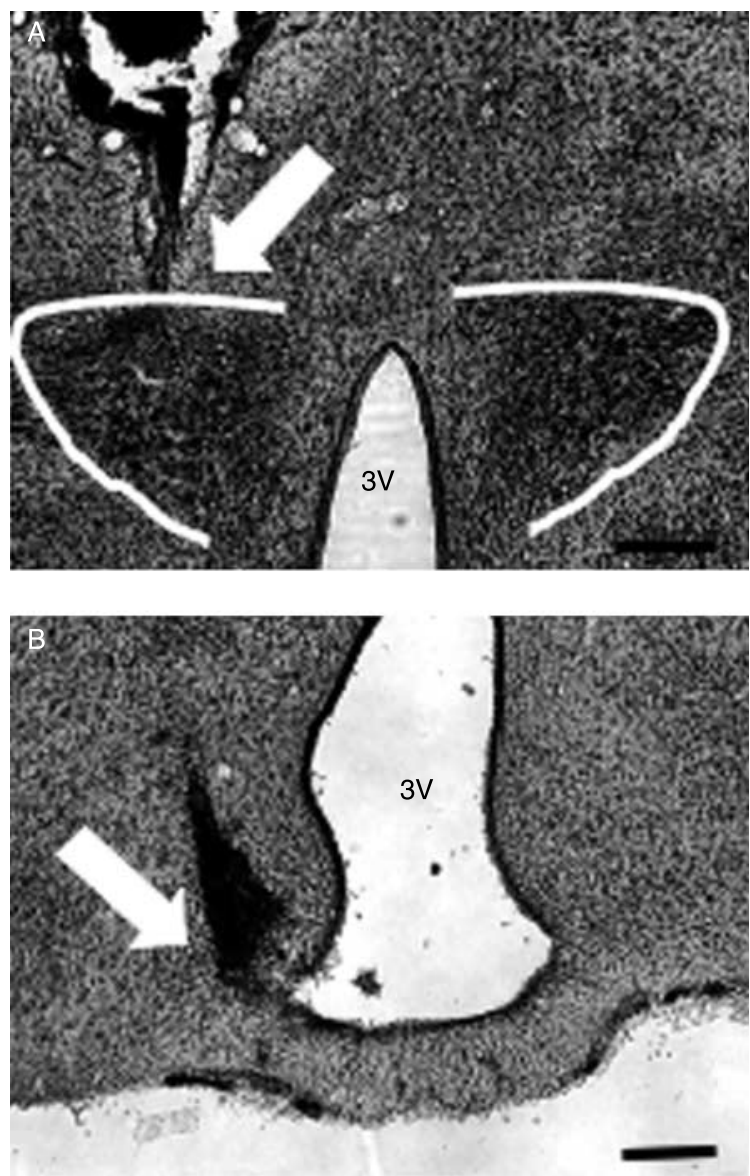

Figure 1 Histological sections showing the location (arrow) of the microinjection needle inserted into the PVN (A) and ARC (B). NissI staining was performed. $3 \mathrm{~V}$, 3rd ventricle. Scale bars, $200 \mu \mathrm{m}$.

Inhibitory effect of ghrelin microinjected into PVN and ARC on noradrenaline release in $B A T$

The total number of rats used for microinjection study into the PVN was 15, and the number of rats in which ghrelin or saline was misplaced was six. The total number of rats used for microinjection study into the ARC was 16 , and the number of rats in which ghrelin or saline was misplaced was seven. The effect of microinjection of ghrelin into the PVN at a dose of $50 \mathrm{pmol}$ on noradrenaline release in BAT is shown in Fig. 2B. There was a significant interaction between ghrelin microinjection and time $\left(F_{8,56}=2.51 ; P<0 \cdot 03\right)$. Further analysis revealed that ghrelin microinjected into the PVN significantly suppressed noradrenaline release in BAT dialysate 0-20 min after the microinjection $(P<0 \cdot 05)$. The effect of the microinjection of ghrelin into the ARC at a dose of 50 pmol on noradrenaline release in BAT is shown in Fig. 2C. There was a significant interaction between ghrelin microinjection and time $\left(F_{8,56}=2 \cdot 62 ; P<0 \cdot 02\right)$. Further analysis revealed that ghrelin microinjected into the ARC significantly decreased noradrenaline release in BAT dialysate
0-20 min after the injection $(P<0 \cdot 05)$. The effect of ghrelin on noradrenaline release in BAT was not detected in misplacement-controls, in which ghrelin was not microinjected into the PVN or ARC correctly.
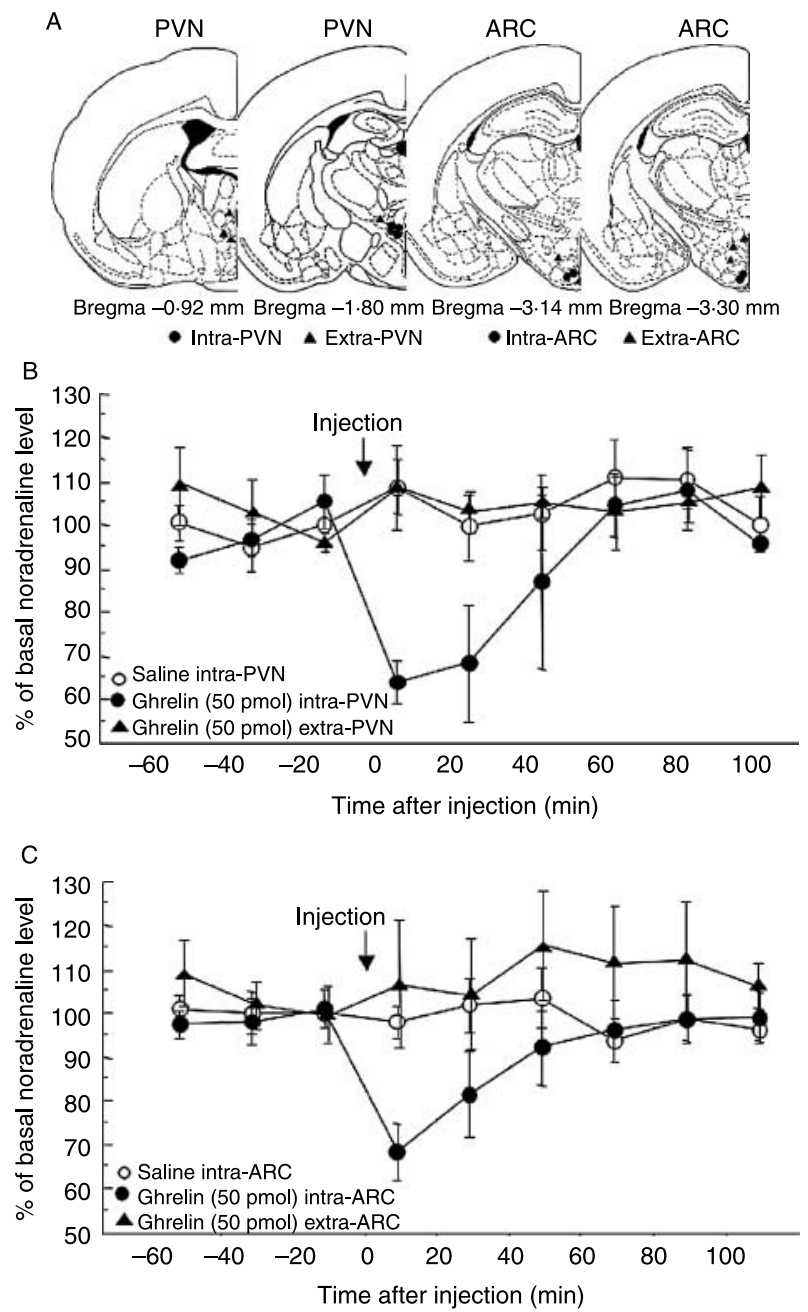

Figure 2 Effect of ghrelin microinjected into the PVN or the ARC on noradrenaline release in BAT. (A) Schematic diagram representing the sites of the tip of the microinjection needle in the PVN and ARC. Filled circles indicate the correct sites (intra-PVN or intra-ARC) and triangles indicate the misplaced sites (extra-PVN or extra-ARC) of microinjection needle tip. Stereotaxic planes were constructed according to the atlas of Paxinos \& Watson (1996). (B) The effect of ghrelin microinjected into the PVN on noradrenaline release in BAT. Open circles, rats microinjected with saline into the PVN $(n=5)$. Filled circles, rats microinjected with ghrelin (50 pmol) into the PVN $(n=4)$ and triangles, rat microinjected with ghrelin $(50 \mathrm{pmol})$ into extra-PVN regions $(n=4)$. (C) The effect of ghrelin microinjected into the ARC on noradrenaline release in BAT. Open circles, rats microinjected with saline into the ARC $(n=5)$. Filled circles, rats microinjected with ghrelin into the ARC (50 pmol; $n=4$ ) and triangles, rat microinjected with ghrelin into extra-ARC regions $(n=4)$. Arrows indicate the time of sample microinjection. Values represent the mean \pm s.E.M. ${ }^{*} P<0 \cdot 05$, compared with the saline group. 

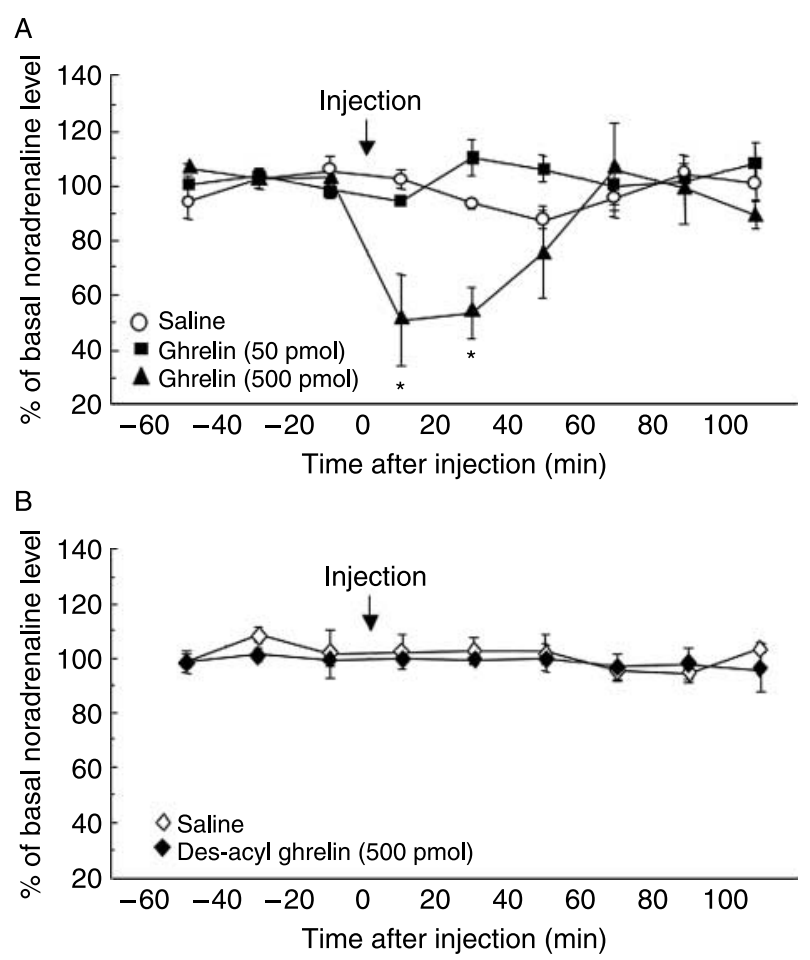

Figure 3 Effect of i.c.v. administration of ghrelin and des-acyl ghrelin on noradrenaline release in BAT. (A) I.c.v. injection of ghrelin significantly decreased noradrenaline release at a dose of 500 pmol but not 50 pmol. Circles, rats injected with saline $(n=4)$. Squares, rats injected with ghrelin $(50 \mathrm{pmol} ; n=4)$. Triangles, rats injected with ghrelin (500 pmol; $n=4$ ). (B) I.c.v. injection of desacyl ghrelin did not influence noradrenaline release. Open diamonds, rats injected with saline $(n=4)$. Filled diamonds, rats injected with des-acyl ghrelin $(500 \mathrm{pmol} ; n=4)$. Arrows indicate the time of sample injection. Values represent the mean \pm s.E.M. ${ }^{*} P<0 \cdot 05$, compared with the saline group.

\section{Inhibitory effect of i.v. ghrelin on noradrenaline release in $B A T$}

The effects of i.v. administration of ghrelin on noradrenaline release in BAT in normal rats and vagotomized rats are shown in Fig. $4 \mathrm{~A}$ and $\mathrm{B}$ respectively. There was a significant interaction between ghrelin injection and time $\left(F_{16,96}=2 \cdot 89\right.$; $P<0 \cdot 001$; Fig. 4A). Further analysis revealed that i.v. administration of ghrelin at a dose of $30 \mathrm{nmol}$, but not $6 \mathrm{nmol}$, significantly decreased noradrenaline release in BAT dialysate $20-40 \mathrm{~min}$ after injection $(P<0 \cdot 05)$. There was a significant ghrelin injection $\times$ operation $\times$ time interaction $\left(F_{8,96}=2 \cdot 12 ; P<0 \cdot 05\right.$; Fig. 4B). The inhibitory effect of i.v. ghrelin on noradrenaline release was blocked by vagotomy. There was no significant difference in basal noradrenaline release in BAT between sham-operated and vagotomized rats (sham, $2 \cdot 00 \pm 0.33 \mathrm{pg} / 20 \mathrm{~min}$; vagotomized, $2 \cdot 22 \pm 0.58 \mathrm{pg} / 20 \mathrm{~min}, P=0 \cdot 78)$.

The effect of i.v. administration of des-acyl ghrelin at a dose of $30 \mathrm{nmol}$ on noradrenaline release in BAT is shown in Fig. 4C. Des-acyl ghrelin did not affect noradrenaline release in BAT.
Northern blotting analysis of Ucp $1 \mathrm{mRNA}$ in BAT

Northern blotting analysis of Ucp1 mRNA in BAT is shown in Fig. 5. There was no significant difference in Ucp1 mRNA expression in BAT between saline group and ghrelin group 3 and $6 \mathrm{~h}$ after their i.c.v. administration (Fig. 5A). There was also no significant difference in Ucp1 mRNA expression in BAT between saline group and ghrelin group 3 and $6 \mathrm{~h}$ after their i.v. administration (Fig. 5B).

\section{RT-PCR analysis of the expression of GHS-R1a}

RT-PCR analysis of GHS-R1a mRNA expression was shown in Fig. 6. There was no band of the PCR products of GHS-R1a in WAT or BAT while it was found in the hypothalamus and pituitary. As internal controls in RT-PCR, GHRH, GH, Ucp1, and leptin were used for the hypothalamus, pituitary, BAT, and WAT respectively, and their PCR products were detected.

\section{Discussion}

The present study is the first study to show that ghrelin administered centrally or peripherally inhibits noradrenaline release in BAT in conscious, free-moving rats, and the results were in accordance with a report that ghrelin administered i.c.v. inhibited the electrophysiological activity of sympathetic nerves in BAT in anesthetized rats (Yasuda et al. 2003). These results suggest that ghrelin inhibits the activity of BAT through the inhibition of the sympathetic nervous system. Ghrelin increases food intake when it is injected i.c.v. or i.v. (Date et al. 2002, Nakazato et al. 2001, Tamura et al. 2001). I.c.v. or s.c. injection of ghrelin elevates RQ in rodents, indicating an inhibitory effect of ghrelin on fat expenditure as an energy substrate (Tschöp et al. 2000). Furthermore, body adipose tissue is reduced in transgenic rats expressing an antisense GHS-R mRNA under the control of the promoter for tyrosine hydroxylase compared with wild rats (Shuto et al. 2002). Together, these results suggest that ghrelin decreases fat expenditure by inhibiting the function of brown adipocytes through the sympathetic nervous system. The i.c.v. or i.v. administration of des-acyl ghrelin, which is known not to bind to GHS-R1a, did not alter the noradrenaline release in BAT. The present study also demonstrated that GHS-R1a mRNA was not detectable in WAT or BAT of rats. These results, therefore, suggest that ghrelin modulates the activity of sympathetic nerves in BAT via GHS-R1a, and that ghrelin does not seem to act directly on brown adipocytes.

BAT plays a major role in energy expenditure and nonshivering thermogenesis in rodents. Noradrenaline released from the sympathetic nerve endings in BAT binds to $\beta_{3}$-adrenergic receptors on brown adipocytes and initiates intracellular breakdown of triglyceride to free fatty acid by activating hormone-sensitive lipase through an intracellular signal, cAMP (Cannon \& Nedergaard 2004). Free fatty acids 


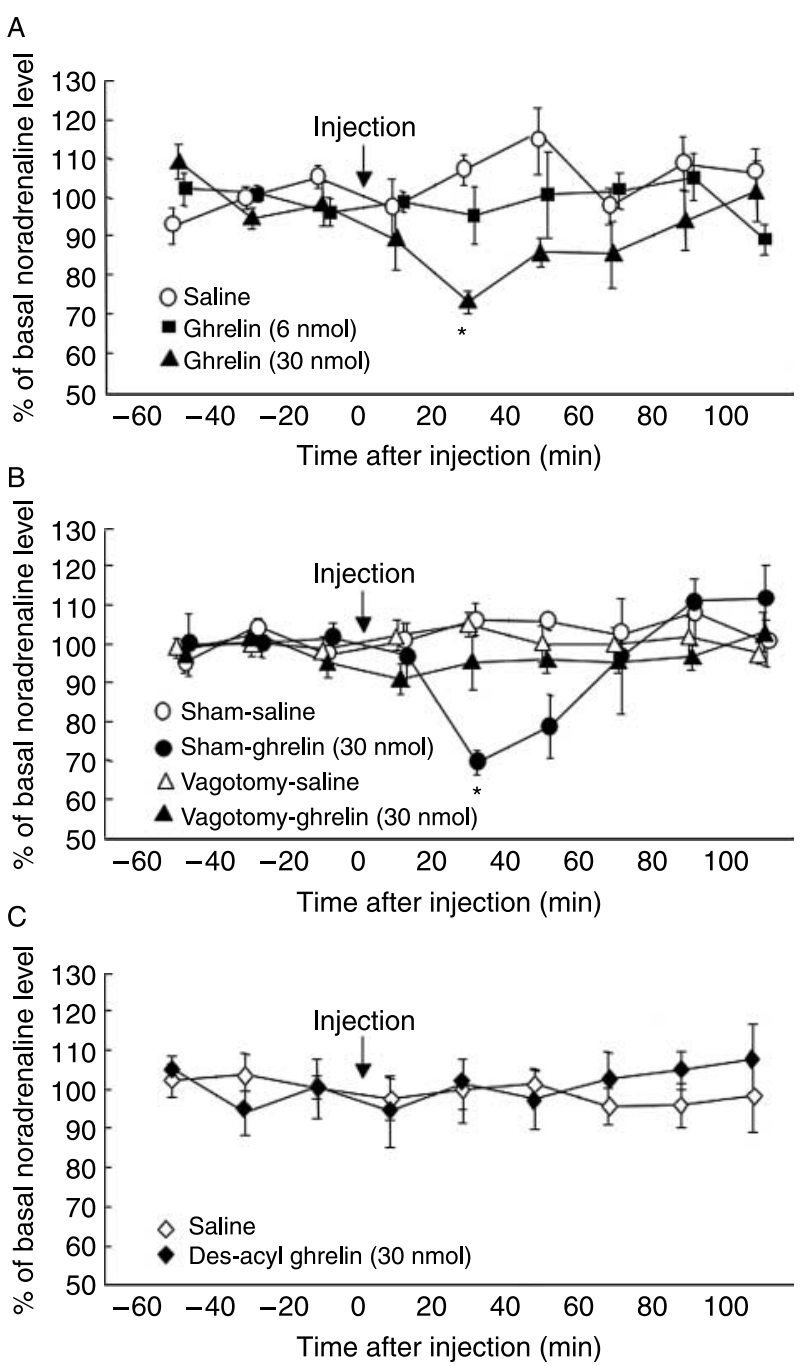

Figure 4 Effect of i.v. administration of ghrelin or des-acyl ghrelin and vagotomy on noradrenaline release in BAT. (A) The effect of i.v. administration of ghrelin on noradrenaline release in BAT. Circles, rats injected with saline $(n=4)$. Squares, rats injected with ghrelin $(6 \mathrm{nmol} ; n=5)$ and triangles, rats injected with ghrelin $(30 \mathrm{nmol}$; $n=6)$. (B) The effect of vagotomy on the suppressive action of ghrelin $(30 \mathrm{nmol})$ on noradrenaline release. Open circles, shamoperated rats injected with saline $(n=4)$. Filled circles, shamoperated rats injected with ghrelin $(30 \mathrm{nmol} ; n=4)$. Open triangles, vagotomized rats injected with saline $(n=4)$. Filled triangles, vagotomized rats injected with ghrelin $(30 \mathrm{nmol} ; n=4)$. (C) The effect of i.v. injection of des-acyl ghrelin on noradrenaline release. Open diamonds, rats injected with saline $(n=4)$. Filled diamonds, rats injected with des-acyl ghrelin $(30 \mathrm{nmol} ; n=4)$. Arrows indicate the time of sample injection. Values represent the mean \pm S.E.M. $* P<0 \cdot 05$, compared with the saline group.

are substrates for thermogenesis and activators of Ucp1 (Cannon \& Nedergaard 2004). Ucp1 is highly expressed in brown adipocytes and is involved in thermogenesis in BAT. The i.c.v. or i.v. injection of ghrelin did not affect the expression level of Ucp1 mRNA in BAT of rats in the present study, while ghrelin inhibits Ucp1 mRNA expression in BAT in a manner independent of ghrelin-induced hyperphagia when it is chronically administered for 7 days (Tsubone et al. 2005, Theander-Carrillo et al. 2006). These findings suggest that chronic administration seems to be necessary for ghrelin to reduce the expression level of Ucp1 mRNA. It is unclear whether ghrelin administered i.c.v. influenced BAT temperature at a dose of $500 \mathrm{pmol}$ in the present study since we did not measure it. However, since a study has shown that i.c.v. infusion of $1 \mathrm{nmol}$ of ghrelin for $10 \mathrm{~min}$ causes a rapid, significant reduction of BAT temperature (Yasuda et al. 2003), further studies are needed to clarify how endogenous ghrelin is involved in the regulatory mechanism of BAT temperature in rats allowed access to chow ad libitum.

The activity of BAT is dependent on the calorie intake. Two-day fasting decreases noradrenaline turnover while cafeteria diet for 9 days increases the turnover in rats (Young et al. 1982). In parallel with the changes in sympathetic nerve activity, $48 \mathrm{~h}$ fasting decreases Ucp1 mRNA expression in rats (Champigny \& Ricquier 1990) while the gene expression is elevated in mice which were exposed to high fat diet for 4 weeks (Surwit et al. 2000). Circulating ghrelin levels show circadian changes in rats allowed access to chow ad libitum (Murakami et al. 2002). In addition to the circadian changes, the circulating ghrelin levels increase in 3-day fasting and decrease on 30-day high fat diet (Lee et al. 2002). These findings therefore suggest that continuous increase or decrease of ghrelin affects the activity of BAT through the sympathetic nerves. Although it is unclear whether ghrelin influences the activities of fat storage-promoting enzymes and fat oxidationpromoting enzymes in rats, an increase in lipid droplets in BAT was found in mice which had been administered with ghrelin i.p. for 7 days $(12 \mathrm{nmol} / \mathrm{kg}$ of body weight per day; Tsubone et al. 2005), These findings, taken together with our results, suggest that ghrelin may inhibit lipolysis in BAT.

The present study showed that ghrelin at a dose of $500 \mathrm{pmol}$ but not 50 pmol inhibits noradrenaline release in BAT while previous studies have shown that ghrelin stimulates food intake and GH secretion at doses of 10 and 20 pmol respectively, when it is administered i.c.v. (Date et al. 2000, Nakazato et al. 2001). The present study also showed that ghrelin at a dose of $30 \mathrm{nmol}$ but not $6 \mathrm{nmol}$ inhibits noradrenaline release in BAT while other studies have shown that ghrelin stimulates food intake and GH secretion at doses of 1.5 and $1.2 \mathrm{nmol}$ respectively, when it is administered i.v. (Date et al. 2002, Tamura et al. 2002). These results suggest that the threshold for ghrelin to suppress noradrenaline release in BAT may be higher than that for ghrelin to stimulate food intake or GH secretion. Another possible explanation for the results is that noradrenaline release in BAT is already suppressed by endogenous ghrelin to some extent in a tonic way, thus requiring higher doses of exogenous ghrelin for further inhibition of noradrenaline release. This seems likely as we have found that i.c.v. administration of $\left[\mathrm{D}-\mathrm{Lys}^{3}\right]-\mathrm{GHRP}$, an GHS-R antagonist, significantly increases noradrenaline release in BAT (Mano-Otagiri, unpublished observation). Furthermore, 
A

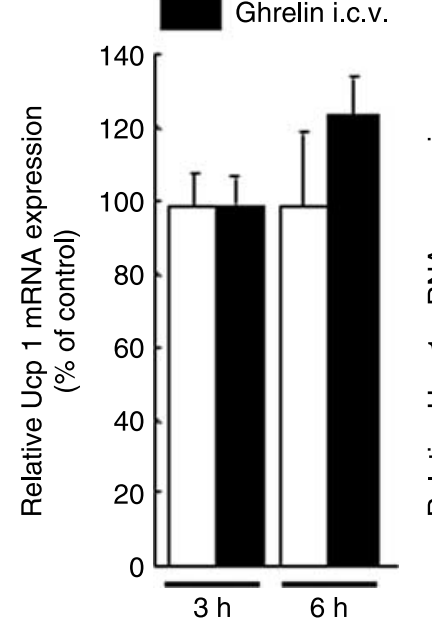

B

B

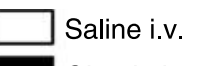

Ghrelin i.v.

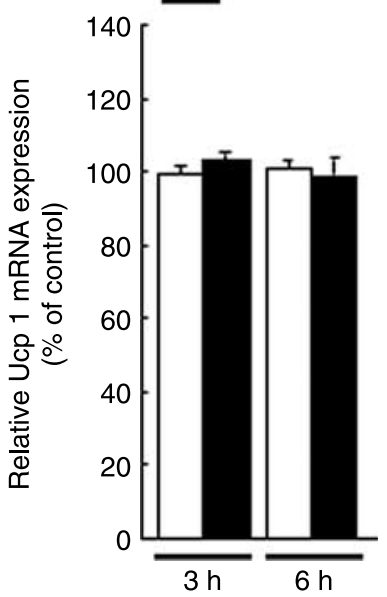

Figure 5 Effect of ghrelin on Ucp1 mRNA expression in BAT. (A) The expression of Ucp1 mRNA in BAT was not influenced by i.c.v. administration of ghrelin (500 pmol) 3 or $6 \mathrm{~h}$ after administration. Open bars, rats injected with saline $(n=5)$. Filled bars, rats injected with ghrelin $(n=6)$. (B) The expression of Ucp1 mRNA in BAT was not influenced by i.v. administration of ghrelin $(30 \mathrm{nmol}) 3$ or $6 \mathrm{~h}$ after administration. Open bars, rats injected with saline $(n=5)$. Filled bars, rats injected with ghrelin $(n=4)$. Values represent the mean \pm S.E.M.

since plasma ghrelin concentrations rise in the afternoon and reach a peak at 1500 in rats allowed access to chow and water ad libitum (Murakami et al. 2002) and the time of ghrelin administration in the present study was around 1400-1500 when endogenous ghrelin concentrations in plasma are suggested to be high, the elevated concentrations of endogenous ghrelin might increase doses of exogenous ghrelin to further inhibit noradrenaline release in BAT.

The present study also shows that a vagotomy blocks the inhibitory effect of i.v. ghrelin on noradrenaline release. It is not likely that ghrelin could not reduce noradrenaline release further because of lowered noradrenaline release in vagotomized rats as there was no significant difference in basal noradrenaline release in BAT between sham-operated and vagotomized rats. It is therefore suggested that the vagal nerve mediates the peripheral ghrelin signal to the central nervous system to inhibit the activity of sympathetic nerves innervating BAT. Recently, it has been suggested that the afferent vagal nerve mediates the stimulatory action of peripherally administered ghrelin on food intake or GH secretion (Date et al. 2002), because GHS-R1a is expressed in $20 \%$ of cells of the vagal nodose ganglion (Burdyga et al. 2006) and the stimulatory effects of peripherally administered ghrelin on food intake and $\mathrm{GH}$ secretion are blocked and attenuated respectively, by vagotomy or capsaicin-induced blockade of vagal afferent signaling (Date et al. 2002). Peripheral ghrelininduced food intake is also abolished by bilateral midbrain transections rostral to the nucleus solitary tract (Date et al. 2006). The nucleus solitary tract mediates the vagal afferent signal to the ARC through its noradrenergic projection. Therefore, the peripheral ghrelin signal to suppress the activity of BAT seems to be transmitted through the afferent vagal nerve and the nucleus solitary tract to the central sympathetic nervous system controlling BAT.

The effects of ghrelin in the PVN and ARC on noradrenaline release in BAT seem to be region-specific as ghrelin did not show the effects when it was microinjected into extra-PVN or -ARC regions. A microinjection of ghrelin into the PVN or ARC increases food intake and RQ in rats (Currie et al. 2005). Since the PVN and ARC express GHS-R1a (Zigman et al. 2006), these findings together with our present results may indicate that ghrelin directly activates GHS-R $1 \mathrm{a}$ in the PVN and ARC and induces a suppressive effect on the sympathetic

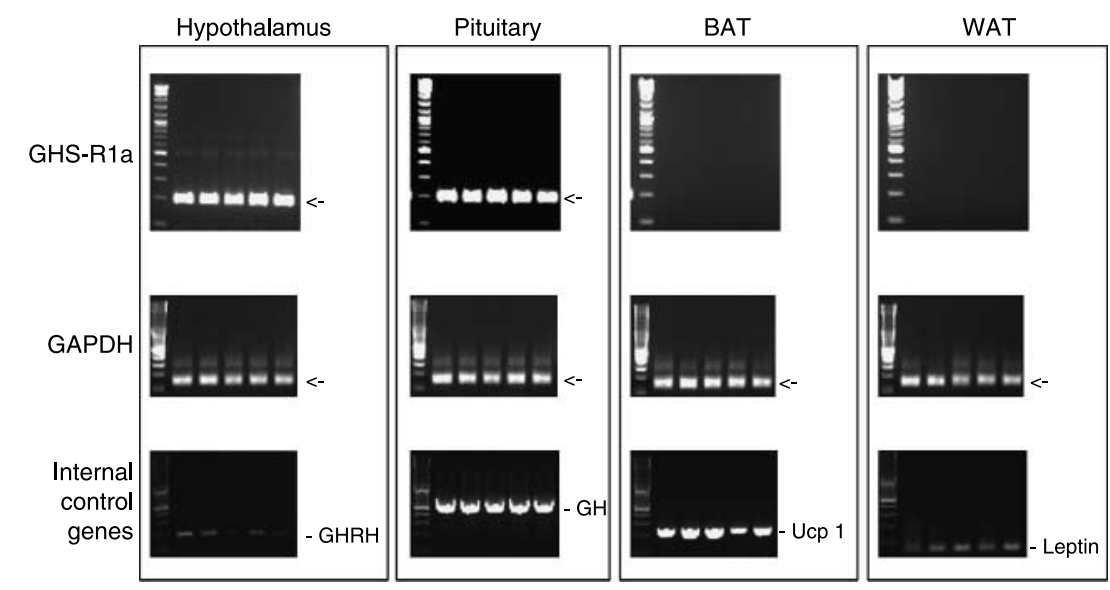

Figure 6 Expression of GHS-R1a mRNA. The band of RT-PCR product of GHS-R1a was not detected in BAT or WAT while it was detected in the hypothalamus and pituitary. The RT-PCR products of GHRH, GH, Ucp1, and leptin were found in the hypothalamus, pituitary, BAT, and WAT respectively, as internal controls. 
nervous system innervating BAT. After injection of the neurotropic virus pseudorabies into BAT, infected neurons were present in the PVN, lateral hypothalamus, perifornical region, and retrochiasmatic nucleus (Oldfield et al. 2002). A slightly longer survival time for virus-infected neurons appeared in the ARC and dorsomedial hypothalamus (Oldfield et al. 2002). Another report indicated that raphe pallidus and the PVN were the main areas containing sympathetic premotor neurons activated by cold exposure (Cano et al. 2003). Since most of these hypothalamic areas express GHS-R1a, it seems that some of these areas are involved in the regulatory mechanism of sympathetic nervous system activity by ghrelin. Although it is unclear if microinjection of ghrelin into the lateral hypothalamus, dorsomedial nucleus, perifornical region, retrochiasmatic nucleus, and raphe pallidus suppresses noradrenaline release in BAT, our results indicate that at least the PVN and ARC may control sympathetic outflow to BAT through activation of GHS-R1a.

In summary, we found that centrally or peripherally administered ghrelin inhibits noradrenaline release in BAT and that a vagotomy blocks the inhibitory effect of peripheral ghrelin on BAT. These results suggest that central and peripheral ghrelin/GHS-R1a may play an important role in the regulatory mechanism of energy metabolism by suppressing the sympathetic nervous system innervating brown adipocytes and that the GHS-R1a expressed in the vagal nerve may be involved in the signal transduction of peripheral ghrelin to control the function of brown adipocytes. It is also suggested that the PVN and ARC may be the sites of ghrelin action in the central nervous system to inhibit the sympathetic outflow controlling brown adipocytes.

\section{Declaration of interest}

The authors declare that there are no conflicts of interest that would prejudice the impartiality of the work reported herein.

\section{Funding}

This study was supported in part by Health and Labor Sciences Research Grants from the Ministry of Health, Labor and Welfare of Japan, Grantsin-Aid for Scientific Research from the Ministry of Education, Culture, Sports, Science and Technology of Japan, and a grant from the Foundation for Growth Science.

\section{Author contribution statement}

Asuka Mano-Otagiri designed the study and wrote the protocol under the instruction of Tamotsu Shibasaki. Hisayuki Ohata, Azusa Iwasaki-Sekino and Takahiro Nemoto contributed to perform the experiments in parts of microinjection, i.v. catheterization and analysis of Ucp1 and GHS-R1a mRNA respectively.

\section{Acknowledgements}

We thank Ms M Iketani for her technical assistance.

\section{References}

Burdyga G, Varro A, Dimaline R, Thompson DG \& Dockray GJ 2006 Ghrelin receptors in rat and human nodose ganglia: putative role in regulating $\mathrm{CB}-1$ and $\mathrm{MCH}$ receptor abundance. American Journal of Physiology. Gastrointestinal and Liver Physiology 290 G1289-G1297.

Cannon B \& Nedergaard J 2004 Brown adipose tissue: function and physiological significance. Physiological Reviews 84 277-359.

Cano G, Passerin AM, Schiltz JC, Card JP, Morrison SF \& Sved AF 2003 Anatomical substrates for the central control of sympathetic outflow to interscapular adipose tissue during cold exposure. Journal of Comparative Neurology 460 303-326.

Champigny O \& Ricquier D 1990 Effects of fasting and refeeding on the level of uncoupling protein mRNA in rat brown adipose tissue: evidence for diet-induced and cold-induced responses. Journal of Nutrition 120 $1730-1736$.

Currie PJ, Mirza A, Fuld R, Park D \& Vasselli JR 2005 Ghrelin is an orexigenic and metabolic signaling peptide in the arcuate and paraventricular nuclei. American Journal of Physiology. Regulatory, Integrative and Comparative Physiology 289 353-358.

Date Y, Murakani N, Kojima M, Kuroiwa T, Matsukura S, Kangawa K \& Nakazato M 2000 Central effects of a novel acylated peptide, ghrelin, on growth hormone release in rats. Biochemical and Biophysical Research Communications 275 477-480.

Date Y, Murakami N, Toshinai K, Matsukura S, Niijima A, Matsuo H, Kangawa K \& Nakazato M 2002 The role of the gastric afferent vagal nerve in ghrelin-induced feeding and growth hormone secretion in rats. Gastroenterology 123 1120-1128.

Date Y, Shimbara T, Koda S, Toshinai K, Ida T, Murakami N, Miyazato M, Kokame K, Ishizuka Y, Ishida Y et al. 2006 Peripheral ghrelin transmits orexigenic signals through the noradrenergic pathway from the hindbrain to the hypothalamus. Cell Metabolism 4 1-9.

Gabaldón AM, Gavel DA, Hamilton JS, McDonald RB \& Horwitz BA 2003 Norepinephrine release in brown adipose tissue remains robust in coldexposed senescent Fischer 344 rats. American Journal of Physiology. Regulatory, Integrative and Comparative Physiology 285 R 91-R 98.

Howard AD, Feighner SD, Cully DF, Arena JP, Liberator PA, Rosenblum CI, Hamelin M, Hreniuk DL, Palyha OC, Anderson J et al. 1996 A receptor in pituitary and hypothalamus that functions in growth hormone release. Science 273 974-977.

Kobelt P, Tebbe JJ, Tjandra I, Stengel A, Bae H, Anderson V, Voort IR, Veh RW, Werner CR, Klapp BF et al. 2005 CCK inhibits orexigenic effect of peripheral ghrelin. American Journal of Physiology. Regulatory, Integrative and Comparative Physiology 288 R751-R758.

Kojima M, Hosoda H, Date Y, Nakazato M, Matsuo H \& Kangawa K 1999 Ghrelin is a growth-hormone-releasing acylated peptide from stomach. Nature 402 656-660.

Lawrence CB, Snape AC, Baudoin FM \& Luckman SM 2002 Acute central ghrelin and $\mathrm{GH}$ secretagogues induce feeding and activate brain appetite centers. Endocrinology 143 155-162.

Lee HM, Wang G, Englander EW, Kojima M \& Greeley GH Jr 2002 Ghrelin, a new gastrointestinal endocrine peptide that stimulates insulin secretion: enteric distribution, ontogeny, influence of endocrine, and dietary manipulations. Endocrinology 143 185-190.

Lowell BB \& Spiegelman BM 2000 Towards a molecular understanding of adaptive thermogenesis. Nature 404 652-660.

Mano-Otagiri A, Nemoto T, Sekino A, Yamauchi N, Shuto Y, Sugihara H, Oikawa S \& Shibasaki T 2006 Growth hormone-releasing hormone (GHRH) neurons in the arcuate nucleus (Arc) of the hypothalamus are decreased in transgenic rats whose expression of ghrelin receptor is attenuated: evidence that ghrelin receptor is involved in the up-regulation of GHRH expression in the Arc. Endocrinology 147 4093-4103.

McKee KK, Palyha OC, Feighner SD, Hreniuk DL, Tan CP, Phillips MS, Smith RG, Van der Ploeg LH \& Howard AD 1997 Molecular analysis of rat pituitary and hypothalamic growth hormone secretagogue receptors. Molecular Endocrinology 11 415-423. 
Murakami N, Hayashida T, Kuroiwa T, Nakahara K, Ida T, Mondal MS, Nakazato M, Kojima M \& Kangawa K 2002 Role for central ghrelin in food intake and secretion profile of stomach ghrelin in rats. Journal of Endocrinology 174 283-288.

Nakazato M, Murakami N, Date Y, Kojima M, Matsuo H, Kangawa K \& Matsukura S 2001 A role for ghrelin in the central regulation of feeding. Nature 409 194-198.

Okada K, Ishii S, Minami S, Sugihara H, Shibasaki T \& Wakabayashi I 1996 Intracerebroventricular administration of the growth hormone-releasing peptide KP-102 increases food intake in free-feeding rats. Endocrinology 137 $5155-5158$.

Oldfield BJ, Giles ME, Watson A, Anderson C, Colvill LM \& Mckinley MJ 2002 The neurochemical characterisation of hypothalamic pathways projecting polysynaptically to brown adipose tissue in the rat. Neuroscience 110 515-526.

Paxinos G \& Watson C 1996 The Rat Brain in Stereotaxic Coordinates. edn 3, San Diego: Academic press.

Rüter J, Kobelt P, Tebbe JJ, Avsar Y, Veh R, Wang L, Klapp BF, Wiedenmann B, Taché Y \& Mönnikes H 2003 Intraperitoneal injection of ghrelin induces Fos expression in the paraventricular nucleus of the hypothalamus in rats. Brain Research 991 26-33.

Sakata I, Yamazaki M, Inoue K, Hayashi Y, Kangawa K \& Sakai T 2003 Growth hormone secretagogue receptor expression in the cells of the stomach-projected afferent nerve in the rat nodose ganglion. Neuroscience Letters 342 183-186.

Shuto Y, Shibasaki T, Otagiri A, Kuriyama H, Ohata H, Tamura H, Kamegai J, Sugihara H, Oikawa S \& Wakabayashi I 2002 Hypothalamic growth hormone secretagogue receptor regulates growth hormone secretion, feeding, and adiposity. Journal of Clinical Investigation 109 1429-1436.

Smith GP, Jerome C, Cushin BJ, Eterno R \& Simansky KJ 1981 Abdominal vagotomy blocks the satiety effect of cholecystokinin in the rat. Science $\mathbf{2 1 3}$ 1036-1037.

Smith RG, Van der Ploeg LHT, Howard AD, Feighner SD, Cheng K, Hickey GJ, Wyvratt MJ Jr, Fisher MH, Nargund RP \& Patchett AA 1997 Peptidomimetic regulation of growth hormone secretion. Endocrine Reviews 18 621-645.
Surwit RS, Dixon TM, Petro AE, Daniel KW \& Collins S 2000 Diazoxide restores $\beta 3$-adrenergic receptor function in diet-induced obesity and diabetes. Endocrinology 141 3630-3637.

Tamura H, Kamegai J, Shimizu T, Ishii S, Sugihara H \& Oikawa S 2002 Ghrelin stimulates GH but not food intake in arcuate nucleus ablated rats. Endocrinology 143 3268-3275.

Tannenbaum GS, Epelbaum J \& Bowers CY 2003 Interrelationship between the novel peptide ghrelin and somatostatin/growth hormone-releasing hormone in regulation of pulsatile growth hormone secretion. Endocrinology 144 967-974.

Theander-Carrillo C, Wiedmer P, Cettour-Rose P, Nogueiras R, Perez-Tilve D, Pfluger P, Castaneda TR, Muzzin P, Schürmann A, Szanto I et al. 2006 Ghrelin action in the brain controls adipocyte metabolism. Journal of Clinical Investigation 116 1983-1993.

Thrivikraman KV, Huot RL \& Plotsky PM 2002 Jugular vein catheterization for repeated blood sampling in the unrestrained conscious rat. Brain Research Protocols 10 84-94.

Tschöp M, Smiley DL \& Heiman ML 2000 Ghrelin induces adiposity in rodents. Nature 407 908-913.

Tsubone T, Masaki T, Katsuragi I, Tanaka K, Kakuma T \& Yoshimatsu H 2005 Ghrelin regulates adiposity in white adipose tissue and UCP1 mRNA expression in brown adipose tissue in mice. Regulatory Peptides 130 97-103.

Yasuda T, Masaki T, Kakuma T \& Yoshimatsu H 2003 Centrally administered ghrelin suppresses sympathetic nerve activity in brown adipose tissue of rats. Neuroscience Letters 349 75-78.

Young JB, Saville E, Rothwell NJ, Stock MJ \& Landsberg L 1982 Effect of diet and cold exposure on norepinephrine turnover in brown adipose tissue of the rat. Journal of Clinical Investigation 69 1061-1071.

Zigman JM, Jones JE, Lee CE, Saper CB \& Elmquist JK 2006 Expression of ghrelin receptor mRNA in the rat and the mouse brain. Journal of Comparative Neurology 494 528-548.

Received in final form 12 March 2009

Accepted 6 April 2009

Made available online as an Accepted Preprint 7 April 2009 